\title{
Literacy and Health Outcomes
}

\author{
A Systematic Review of the Literature
}

Darren A. DeWalt, MD, MPH, Nancy D. Berkman, PhD, Stacey Sheridan, MD, MPH, Kathleen

N. Lohr, PhD, Michael P. Pignone, MD, MPH

OBJECTIVE: To review the relationship between literacy and health outcomes.

DATA SOURCES: We searched MEDLINE, Cumulative Index to Nursing and Allied Health (CINAHL), Educational Resources Information Center (ERIC), Public Affairs Information Service (PAIS), Industrial and Labor Relations Review (ILLR), PsychInfo, and Ageline from 1980 to 2003.

STUDY SELECTION: We included observational studies that reported original data, measured literacy with any valid instrument, and measured one or more health outcomes. Two abstractors reviewed each study for inclusion and resolved disagreements by discussion.

DATA EXTRACTION: One reviewer abstracted data from each article into an evidence table; the second reviewer checked each entry. The whole study team reconciled disagreements about information in evidence tables. Both data extractors independently completed an 11-item quality scale for each article; scores were averaged to give a final measure of article quality.

DATA SYNTHESIS: We reviewed 3,015 titles and abstracts and pulled 684 articles for full review; 73 articles met inclusion criteria and, of those, 44 addressed the questions of this report. Patients with low literacy had poorer health outcomes, including knowledge, intermediate disease markers, measures of morbidity, general health status, and use of health resources. Patients with low literacy were generally 1.5 to 3 times more likely to experience a given poor outcome. The average quality of the articles was fair to good. Most studies were cross-sectional in design; many failed to address adequately confounding and the use of multiple comparisons.

CONCLUSIONS: Low literacy is associated with several adverse health outcomes. Future research, using more rigorous

Received from the RTI International-University of North Carolina Evidence-based Practice Center (DAD, NDB, SS, KNL, MPP), Research Triangle Park, NC; Robert Wood Johnson Clinical Scholars Program (DAD, MPP); Cecil G. Sheps Center for Health Services Research (MPP), University of North Carolina at Chapel Hill; and Divisions of General Internal Medicine (DAD, SS, MPP) and Community Pediatrics (DAD), University of North Carolina School of Medicine, Chapel Hill, NC.

Address correspondence and requests for reprints to Dr. DeWalt: 5039 Old Clinic Building, CB\# 7110, Chapel Hill, NC 27599 (e-mail: dewaltd@med.unc.edu). methods, will better define these relationships and guide developers of new interventions.

KEY WORDS: health literacy; health outcomes; systematic review.

J GEN INTERN MED 2004;19:1228-1239.

$\mathbf{L}$ ow literacy is common in the United States. In 1993, the National Adult Literacy Study reported that 90 million adult Americans scored in the lowest 2 levels of a 5-level scale intended to assess the degree of proficiency to function in society and achieve one's goals. ${ }^{1}$ Those who score at the lowest 2 levels have difficulty integrating information from complex texts or documents and performing calculations requiring two or more sequential operations. ${ }^{1}$ In the 1990s, evidence began to emerge about the prevalence of low literacy in health care settings and its adverse influence on health outcomes. ${ }^{2,3}$ In February 1999, the American Medical Association (AMA) Council on Scientific Affairs recommended the allocation of federal and private funds for research in this area. ${ }^{4}$

Researchers and policy makers often use the phrase "health literacy" to describe a set of skills needed to function in the health care environment. To date, however, research in this area has focused on the relationship between reading ability and a variety of health outcomes. In most cases, reading ability was measured with one of three instruments (Table 1). No studies have measured the value of health literacy as a broader construct. $^{5}$

In 2003, at the AMA's request, the Agency for Healthcare Research and Quality (AHRQ) commissioned a systematic review and analysis from the RTI InternationalUniversity of North Carolina Evidence-based Practice Center (RTI-UNC EPC) on the evidence for the etiologic relationship between literacy and health outcomes and the effectiveness of interventions to mitigate the impact of low literacy. The full evidence report, available at www.ahrq.gov, was intended to inform clinical practice and health policy and lay a foundation for the next wave of research in literacy and health. ${ }^{6}$ This article summarizes the etiologic relationship results; the full report reviews studies of interventions. ${ }^{7}$ 
Table 1. Instruments Used to Measure Reading Ability

\begin{tabular}{|c|c|c|c|c|c|c|c|}
\hline Instrument & $\begin{array}{l}\text { Method of } \\
\text { Assessment }\end{array}$ & Type of Score & $\begin{array}{l}\text { Health } \\
\text { Focus }\end{array}$ & Description of Test & Validation & Advantages & Disadvantages \\
\hline $\begin{array}{l}\text { Wide Range } \\
\text { Achievement } \\
\text { Test (WRAT) }^{14}\end{array}$ & $\begin{array}{l}\text { Word } \\
\text { recognition } \\
\text { and } \\
\text { pronunciation }\end{array}$ & $\begin{array}{l}\text { 1. Continuous score } \\
\text { 2. Grade level }\end{array}$ & No & $\begin{array}{l}\text { Offers two equivalent alternate } \\
\text { test forms, to be used } \\
\text { individually or in } \\
\text { combination for } \\
\text { comprehensive test results. } \\
\text { Can be used for persons } \\
\text { ages } 5 \text { to } 75 \text { years. Standard } \\
\text { scores and percentiles } \\
\text { compare individual } \\
\text { performance with that of } \\
\text { others of the same age. } \\
\text { Length about } 10 \text { minutes. }\end{array}$ & $\begin{array}{l}\text { Content: compared to } \\
\text { vocabulary taught in K } \\
\text { through 12th grades- } \\
\text { strong evidence. } \\
\text { Construct/criterion: age, } \\
\text { cognitive ability, WRAT- } \\
\text { R, Rasch model, } \\
\text { standardized } \\
\text { achievement tests, } \\
\text { discriminate analysis- } \\
\text { strong evidence. }\end{array}$ & $\begin{array}{l}\text { Standard by which } \\
\text { others are } \\
\text { compared. Well } \\
\text { validated and } \\
\text { studied. } \\
\text { Relatively short } \\
\text { to administer. }\end{array}$ & $\begin{array}{l}\text { Does not test } \\
\text { comprehension. } \\
\text { Words not chosen } \\
\text { from health care } \\
\text { context. Not } \\
\text { available in } \\
\text { Spanish. }\end{array}$ \\
\hline $\begin{array}{l}\text { Rapid Estimate of } \\
\text { Adult Literacy } \\
\text { in Medicine } \\
\text { (REALM) }^{11}\end{array}$ & $\begin{array}{l}\text { Word } \\
\text { recognition } \\
\text { and } \\
\text { pronunciation }\end{array}$ & $\begin{array}{l}\text { 1. Continuous score } \\
\text { 2. Grade level }\end{array}$ & Yes & $\begin{array}{l}\text { Designed to be used in public } \\
\text { health and primary care } \\
\text { settings to identify patients } \\
\text { with low reading levels. } \\
\text { Provides reading estimates } \\
\text { for patients who read below } \\
\text { a 9th grade level. Length } \\
\text { about } 2 \text { to } 3 \text { minutes. }\end{array}$ & $\begin{array}{l}\text { Content: words taken from } \\
\text { patient education } \\
\text { materials or forms. } \\
\text { Criterion: compared to } \\
\text { SORT*, PIAT, }^{\dagger} \text { and } \\
\text { WRAT—strong }^{\text {evidence. }}{ }^{1,62}\end{array}$ & $\begin{array}{l}\text { Extremely easy } \\
\text { and quick to } \\
\text { administer. } \\
\text { Highly } \\
\text { correlated with } \\
\text { other reading } \\
\text { tests. Words } \\
\text { chosen from } \\
\text { health context. }\end{array}$ & $\begin{array}{l}\text { Does not test } \\
\text { comprehension. } \\
\text { Only relies on word } \\
\text { recognition. Does } \\
\text { not measure ability } \\
\text { above 9th grade } \\
\text { level. Not available } \\
\text { in Spanish. }\end{array}$ \\
\hline $\begin{array}{l}\text { Test of Functional } \\
\text { Health Literacy } \\
\text { in Adults } \\
\text { (TOFHLA) }^{12}\end{array}$ & $\begin{array}{l}\text { Prompts and } \\
\text { modified } \\
\text { Cloze }^{\ddagger} \text { method }\end{array}$ & $\begin{array}{l}\text { 1. Continuous score } \\
\text { 2. Categorical score: } \\
\text { determined by } \\
\text { developer as } \\
\text { inadequate } \\
\text { (individuals will often } \\
\text { be unable to read and } \\
\text { interpret health texts), } \\
\text { marginal (individuals } \\
\text { will often have } \\
\text { difficulty reading and } \\
\text { interpreting health } \\
\text { texts), and adequate } \\
\text { (individuals will be able } \\
\text { to read and interpret } \\
\text { most health texts). }{ }^{12}\end{array}$ & Yes & $\begin{array}{l}\text { Used to measure functional } \\
\text { health literacy-both } \\
\text { numeracy and reading } \\
\text { comprehension-using } \\
\text { health-related materials. } \\
\text { Available in Spanish and } \\
\text { English. Length about } 20 \text { to } \\
25 \text { minutes. Also available in } \\
\text { a short form (S-TOFHLA) } \\
\text { that only uses two reading } \\
\text { comprehension passages } \\
\text { (about } 5 \text { to } 10 \text { minutes). }\end{array}$ & $\begin{array}{l}\text { Content: used actual } \\
\text { hospital medical } \\
\text { instructions for the } \\
\text { items. Criterion: } \\
\text { compared to REALM and } \\
\text { WRAT with high } \\
\text { correlations. }{ }^{63}\end{array}$ & $\begin{array}{l}\text { Good face validity. } \\
\text { Requires some } \\
\text { comprehension. } \\
\text { Measures } \\
\text { facility with } \\
\text { basic medical } \\
\text { calculations. } \\
\text { Available in } \\
\text { Spanish and } \\
\text { English. }\end{array}$ & $\begin{array}{l}\text { Lengthy } \\
\text { administration. } \\
\text { Difficult to sort out } \\
\text { score from } \\
\text { "numeracy" from } \\
\text { score on "reading } \\
\text { comprehension." }\end{array}$ \\
\hline
\end{tabular}

* The SORT is the Slosson Oral Reading Test, a standardized reading recognition test.

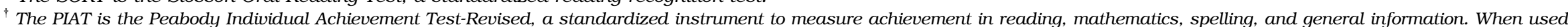
in these validation studies, the reading recognition component was used.

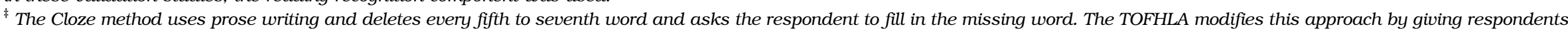
a choice of 4 possibilities for every deleted word. 


\section{METHODS}

To develop a plan for the systematic review, we conducted two conference calls including the research team and the project's Technical Expert Advisory Group (TEAG). ${ }^{6}$ The TEAG is a group of 8 researchers and practitioners considered expert in the field of literacy and health. They served as advisors for this report. Based on the AHRQ's initial commission and the TEAG's advice, we constructed key questions for the systematic review.

\section{Key Questions}

We examined the following key questions:

1. Are literacy skills related to the use of health care services?

2. Are literacy skills related to health outcomes?

3. Are literacy skills related to the costs of health care?

4. Are literacy skills related to disparities in health outcomes according to race, ethnicity, culture, or age?

\section{Inclusion and Exclusion Criteria}

Based on the key questions, we generated a list of inclusion and exclusion criteria (Table 2). We limited studies to those with outcomes related to health and health services and measurement of literacy skills with a valid instrument. We defined a valid instrument as one that had previously been used in a published study or compared with other published instruments. Instruments with a high level of face validity that were validated in the study in question were allowed. Studies were not systematically excluded if they measured other aspects of literacy (writing or listening), but no studies were found to address these other categories. To ensure that the studies reviewed were relevant to current practice in the United States, we decided to restrict our search to more current literature (1980 publication to the present) and to studies conducted in developed countries. Because much of the research on literacy and health has focused on understanding health information, we included studies on the relationship between literacy and health knowledge pertaining to health care services and health outcomes.

\section{Literature Search and Retrieval Process}

Databases and Search Terms. We searched 7 databases listed in Table 3 using the following key words: literacy, numeracy, WRAT, Wide Range achievement, rapid estimate of adult, TOFHLA, test of functional health, reading ability, and reading skill. For databases that we expected to cover a variety of literacy issues, we used only the term "health literacy" to limit our search results. To identify additional relevant literature, we reviewed the National Library of Medicine Current Bibliography in Medicine-Health Literacy ${ }^{8}$ and the Annotated Bibliographies at the Harvard School of Public Health Department of Health Literacy Studies (www.hsph.harvard.edu/healthliteracy / literature.html). ${ }^{9}$
Table 2. Literature Searches: Inclusion and Exclusion Criteria

Study population

All races, ethnicities, and cultural groups.

Patients of all ages and caregivers whose primary language is the same as that of the health care provider and/or intervention.

Study settings and geography Studies conducted in the developed world including North America, Australia, New Zealand, Japan, and Europe.

Time period

Published from 1980 to the present.

Publication criteria

English only.

Articles in print.

Excluded were articles accepted for publication before appearance in the journal, articles in the so-called gray literature, and articles we could not obtain during the review period.

Admissible evidence (study design and other criteria) Original research studies that provided sufficient detail regarding methods and results to enable use and adjustment of the data and results.

Eligible study designs included:

Observational studies: prospective and retrospective cohort studies, case-control studies, and cross-sectional studies.

Relevant outcomes must be able to be abstracted from data presented in the papers.

Single case reports or small case series (fewer than 10 subjects) were excluded.

Other study exclusion criteria included studies:

Of dyslexia and dementia;

With no original data;

With no health outcomes;

With an outcome limited to satisfaction or likeability of one intervention material compared to another;

That measured outcome only by a Cloze test of comprehension (but studies that used literacy measurements that included a Cloze test were retained);

Did not measure literacy in study participants; and

Concerning the basic experimental science of reading ability (e.g., studies of brain function including results from magnetic resonance imaging or electroencephalogram).

We also solicited articles from experts in the field, including the TEAG.

Article Selection and Review. One reviewer initially evaluated abstracts for inclusion or exclusion. If that reviewer concluded the article should be included, we retained it for full article review; if he or she thought the article should be excluded, a second reviewer examined the abstract. In the next phase, two authors reviewed the remaining full articles. If both reviewers agreed that an article did not meet inclusion criteria, the article was excluded from further analysis. Disagreements were reconciled by the entire study team. For the articles that met inclusion criteria, the first reviewer (MPP, $\mathrm{SS}$, or DAD) initially entered data from an article into the evidence table and the second reviewer (NDB) checked each article and edited all table entries for accuracy and consistency. 
Table 3. Literacy Search Strategy, Yield, and Final Count of Articles

\begin{tabular}{|c|c|c|c|c|c|c|}
\hline $\begin{array}{l}\text { Database and } \\
\text { Search Strategy }\end{array}$ & $\begin{array}{l}\text { Total } \\
\text { References } \\
\text { Identified }\end{array}$ & $\begin{array}{l}\text { Unduplicated } \\
\text { References }\end{array}$ & $\begin{array}{l}\text { Articles Excluded } \\
\text { at Abstract } \\
\text { Review Phase }\end{array}$ & $\begin{array}{l}\text { Articles } \\
\text { Retained } \\
\text { for Full Review }\end{array}$ & $\begin{array}{l}\text { Articles } \\
\text { Rejected After } \\
\text { Full Review }\end{array}$ & $\begin{array}{l}\text { Articles } \\
\text { Included }\end{array}$ \\
\hline MEDLINE* & 2,065 & 2,065 & 1,599 & 466 & 399 & 67 \\
\hline $\begin{array}{l}\text { CINAHL } \\
\text { Literacy, numeracy }\end{array}$ & 932 & 633 & 446 & 187 & 183 & 4 \\
\hline $\begin{array}{l}\text { PsychInfo } \\
\text { Health literacy }\end{array}$ & 45 & 20 & 13 & 7 & 6 & 1 \\
\hline $\begin{array}{l}\text { ERIC } \\
\text { Health literacy }\end{array}$ & 25 & 23 & 8 & 14 & 14 & 0 \\
\hline $\begin{array}{l}\text { Ageline } \\
\text { Health literacy }\end{array}$ & 13 & 9 & 4 & 5 & 5 & 0 \\
\hline $\begin{array}{l}\text { Cochrane } \\
\text { Library Literacy }\end{array}$ & 8 & 0 & 0 & 0 & 0 & 0 \\
\hline $\begin{array}{l}\text { PAIS } \\
\text { Health literacy }\end{array}$ & 49 & 0 & 0 & 0 & 0 & 0 \\
\hline $\begin{array}{l}\text { ILRR } \\
\text { Health literacy }\end{array}$ & 0 & 0 & 0 & 0 & 0 & 0 \\
\hline $\begin{array}{l}\text { NLM Current Bibliographies } \\
\text { in Medicine-Health Literacy }\end{array}$ & 479 & 177 & 177 & 0 & 0 & 0 \\
\hline $\begin{array}{l}\text { Harvard School of Public } \\
\text { Health, Department of } \\
\text { Health Literacy Studies }\end{array}$ & 241 & 83 & 83 & 0 & 0 & 0 \\
\hline Expert Additions & 11 & 5 & 0 & 5 & 4 & 1 \\
\hline totals & 3,868 & 3,015 & 2,330 & 684 & 611 & 73 \\
\hline
\end{tabular}

* Key word search: literacy, numeracy, WRAT, Wide Range achievement, rapid estimate of adult, TOFHLA, test of functional health, reading ability, reading skill.

WRAT, Wide Range Achievement Test; TOFHLA, Test of Functional Health Literacy in Adults; CINAHL, Cumulative Index to Nursing and Allied Health; ERIC, Educational Resources Information Center; PAIS, Public Affairs Information Service; ILRR, Industrial and Labor Relations Review; NLM, National Library of Medicine.

The two abstractors or the entire study team reconciled all disagreements about information in the evidence tables.

\section{Evaluation of Quality and Strength of Evidence}

Rating the Quality of Individual Articles. We assessed the quality of included articles based on criteria adapted from West et al. ${ }^{10}$ We graded each study according to the adequacy of study population, comparability of subjects, validity and reliability of the literacy measurement, maintenance of comparable groups, appropriateness of the outcome measurement, appropriateness of statistical analysis, and adequacy of control of confounding.

We converted our quality ratings for each item into numeric values $(0=$ poor, $1=$ fair , and $2=$ good $)$ and created a composite rating for each study, giving each item equal weight; we excluded items judged not applicable based on study design. We totaled the score for each evaluator and then averaged the results for applicable elements. We reconciled ratings in which one rater provided a score for the item and the second said the item was not applicable. Although our rating scale is based on the best available evidence for this type of assessment, it should be interpreted with caution, as it has not been validated.

\section{Peer Review Process}

AHRQ staff and a wide array of clinicians, researchers, representatives of professional societies, and potential users reviewed the draft evidence report. The EPC authors revised the report, where appropriate, taking these external review comments into account.

\section{RESULTS}

Table 3 shows the full search results. Of the 73 articles that met eligibility criteria, 44 articles informed the key questions for this paper. The main reasons for exclusion were no original data ( $48 \%$ of articles), no health outcome (34\% of articles), and no measure of literacy ( $10 \%$ of articles). Study designs included cross-sectional studies (32), cohort studies (9), case-control studies (2), and retrospective case series (1).

The number of participants enrolled ranged from 34 to 3,260 . Most studies presented descriptive information on participants' age, ethnicity, and education; about half reported participants' income levels. Sixteen studies included information about the participants' insurance status, but only 4 included insurance in a multivariate analysis.

Literacy was most often measured with the Rapid Estimate of Adult Literacy in Medicine (REALM, 13), ${ }^{11}$ the 
Test of Functional Health Literacy in Adults (TOFHLA or the short version S-TOFHLA, 15), ${ }^{12,13}$ or the Wide Range Achievement Test (WRAT, 6), and characteristics of these instruments are presented in Table $1 .{ }^{14}$ The range and distribution of literacy levels varied widely among studies. Research teams usually analyzed literacy as a categorical variable but tended to use different cutoff levels.

Table 4 summarizes all identified and included studies and their findings. Of the 44 studies, we graded 25 as good, 16 as fair, and 3 as poor. We generally focus on the goodquality studies here, but when no good-quality study was performed, we discuss the available evidence.

\section{Relationship Between Reading Ability and Knowledge Outcomes}

Sixteen studies measured the relationship between reading ability and knowledge of health outcomes or health services (Table 4). ${ }^{15-30}$ Eight were graded as good quality. ${ }^{15-19,21-23}$ In general, these studies found a positive and significant relationship between reading ability and participants' knowledge of these health services or health outcomes. Only 2 studies did not find a statistically significant positive relationship $^{18,25} ; 1$ was clearly underpowered. ${ }^{25}$

\section{Relationship Between Reading Ability and the Use of Health Care Services}

Physician Visits. One good-quality cross-sectional study found no statistically significant relationship between literacy and number of self-reported health care visits after adjusting for age, health status, and economic indicators. ${ }^{31}$ One small, fair-quality cross-sectional study reported that lower literacy patients had 3 times the number of outpatient visits as higher literacy patients, but statistical tests were not reported. ${ }^{32}$

Screening and Prevention. Two studies evaluated the relationship between reading ability and health promotion and disease prevention. ${ }^{33,34}$ In a good-quality cross-sectional study, Scott et al. found that, after controlling for age, gender, race, education, and income, Medicare enrollees with lower literacy had a greater odds of never having had a Pap smear (odds ratio [OR], 1.7; 95\% confidence interval [CI], 1.0 to 3.1) and not having a mammogram in the past 2 years (OR, 1.5; $95 \%$ CI, 1.0 to 2.2 ) than patients with higher literacy. ${ }^{33}$

In the same study by Scott et al., patients with lower literacy were more likely to report not receiving influenza (OR, 1.4; 95\% CI, 1.1 to 1.9 ) and pneumococcal immunizations (OR, 1.3; 95\% CI, 1.1 to 1.7 ) compared to patients with higher literacy after adjustment for age, gender, race, education, and income. ${ }^{33}$

Hospitalization. Two good-quality prospective cohort studies showed, in adjusted analyses, that a lower literacy level was significantly associated with increased risk of hospitalization. ${ }^{35,36}$ The odds of hospitalization at a public hospital over 1 year were 1.69 times higher (95\% CI, 1.13 to 2.53) for patients with lower literacy than for patients with higher literacy, after adjusting for age, gender, race, health status, receiving financial assistance, and health insurance, but not for education. ${ }^{36}$ In the second study, the odds of being hospitalized among Medicare enrollees were 1.29 times higher (95\% CI, 1.07 to 1.55) for patients with lower literacy than for patients with higher literacy after adjusting for age, gender, race/ethnicity, language, income, and educational status. ${ }^{35}$

\section{Relationship Between Reading Ability and Health Outcomes}

Adherence. Two good-quality studies evaluated the relationship between literacy and medication adherence and found conflicting results. ${ }^{37,38}$ Two fair-quality studies evaluated adherence to research or therapy visit schedules. ${ }^{39,40}$

Both Golin et al. and Kalichman et al. measured adherence to antiretroviral therapy for HIV infection in good-quality studies. Golin et al. measured adherence prospectively over 48 weeks using electronic bottle caps, pill counts, and self-reports among 117 patients in a university HIV clinic. ${ }^{38}$ They found no bivariate relationship between literacy and adherence $(r=-.01 ; P=.88)$, and did not perform multivariate analyses. Kalichman et al. measured self-reported adherence in 184 patients; lower literacy was associated with a greater odds of poor adherence (OR, 3.9; 95\% CI, 1.1 to 13.4), defined as recall of missing any dose during the previous 48 hours, ${ }^{37}$ after adjustments for race, income, social support, and education.

Health Behaviors. One good-quality cross-sectional study found that asthma patients with higher literacy had better metered dose inhaler technique based on measuring the number of steps performed correctly (difference in number of correct steps out of 6 steps = 1.3 steps; $95 \%$ CI, 0.9 to 1.7). ${ }^{23}$ Analyses were adjusted for education and whether the patient had a regular source of care.

One good-quality study ${ }^{21}$ and 2 fair-quality studies ${ }^{41,42}$ evaluated the relationship between literacy and smoking. The best study was a cross-sectional study that evaluated the relationship between literacy and smoking practices among 600 pregnant women. The investigators found no difference in the unadjusted rates of smoking according to literacy status, but they did not perform adjusted analyses for relevant confounders. ${ }^{21}$

One good-quality ${ }^{43}$ study and 2 fair-quality ${ }^{42,44}$ studies evaluated behavior problems of children or adolescents. Davis et al. studied 386 adolescents from low-income neighborhoods and found that, after controlling for age, race, and gender, youth who were more than 2 grades behind expected reading level (Slosson Oral Reading Test) were more likely than others to carry a weapon, take a weapon to school, miss school because it was unsafe, and be in a physical fight that required medical treatment than youth who were at the expected reading level. ${ }^{43}$ 
Table 4. Published Studies Evaluating the Relationship Between Literacy and Health Outcomes

\begin{tabular}{|c|c|c|c|c|}
\hline Reference & Instrument/Cut-points & Outcome & Literacy Relationship & Quality \\
\hline \multicolumn{5}{|l|}{ Knowledge } \\
\hline Davis et al. ${ }^{15}$ & REALM/continuous & Knowledge about mammography & $\begin{array}{l}\text { Correlation between literacy and } \\
\text { low knowledge } r \sim .2(P<.001)\end{array}$ & G \\
\hline Lindau et al. ${ }^{16}$ & REALM/9th grade & $\begin{array}{l}\text { Acceptable knowledge of cervical } \\
\text { cancer screening }\end{array}$ & HL OR, $2.25[1.1$ to 4.8$]$ & $\mathrm{G}$ \\
\hline Miller et al. ${ }^{17}$ & S-TOFHLA/continuous & HIV medication knowledge & $\begin{array}{l}\text { Correlated with literacy, } r=.31 \\
\quad(P=.005)\end{array}$ & $\mathrm{G}$ \\
\hline Moon et al. ${ }^{18}$ & REALM/continuous & $\begin{array}{l}\text { Parental knowledge about child } \\
\text { health care }\end{array}$ & No relationship & $\mathrm{G}$ \\
\hline Spandorfer et al. ${ }^{19}$ & WRAT/continuous & $\begin{array}{l}\text { Comprehension of emergency } \\
\text { department discharge } \\
\text { instructions }\end{array}$ & LL less knowledge & $\mathrm{G}$ \\
\hline Arnold et al. ${ }^{21}$ & REALM/continuous & Knowledge about smoking & LL less knowledge & $\mathrm{G}$ \\
\hline Williams et al. ${ }^{23}$ & REALM/grade categories & Knowledge about asthma & LL less knowledge & $\mathrm{G}$ \\
\hline Williams et al. $^{22}$ & S-TOFHLA/IMA & $\begin{array}{l}\text { Knowledge of hypertension } \\
\text { Knowledge of diabetes }\end{array}$ & $\begin{array}{l}\text { LL less knowledge LL less } \\
\text { knowledge }\end{array}$ & $\mathrm{G}$ \\
\hline Gazmararian et al. ${ }^{26}$ & S-TOFHLA/IMA & $\begin{array}{l}\text { Knowledge about reproductive } \\
\text { health }\end{array}$ & LL less knowledge & $\mathrm{F}$ \\
\hline Kalichman et al. ${ }^{28}$ & $\begin{array}{l}\text { TOFHLA RC only/80\% } \\
\text { correct }\end{array}$ & Knowledge about HIV & LL have less knowledge & $\mathrm{F}$ \\
\hline $\begin{array}{l}\text { Kalichman and } \\
\text { Rompa }^{27}\end{array}$ & $\begin{array}{l}\text { TOFHLA RC only/80\% } \\
\text { correct }\end{array}$ & Knowledge about HIV & $\begin{array}{l}\text { LL score } 7.5, \text { HL score } 7.8 \\
\quad(P<.01)\end{array}$ & $\mathrm{F}$ \\
\hline Kalichman et al. ${ }^{29}$ & $\begin{array}{l}\text { TOFHLA RC only } / 85 \% \\
\text { correct }\end{array}$ & $\begin{array}{l}\text { HIV patient knows CD4 count } \\
\text { HIV patient knows viral load }\end{array}$ & $\begin{array}{l}\text { HL more likely to know HL more } \\
\text { likely to know }\end{array}$ & $\mathrm{F}$ \\
\hline Miller et al. ${ }^{30}$ & WRAT/continuous & $\begin{array}{l}\text { Understanding of } \\
\text { informed consent }\end{array}$ & LL less understanding & $\mathrm{F}$ \\
\hline $\begin{array}{l}\text { Wilson and } \\
\text { McLemore }^{25}\end{array}$ & REALM/continuous & $\begin{array}{l}\text { Knowledge of self-care after } \\
\text { orthopedic surgery }\end{array}$ & No relationship & $\mathrm{F}$ \\
\hline $\begin{array}{l}\text { Conlin and } \\
\text { Schumann }^{24}\end{array}$ & REALM/continuous & $\begin{array}{l}\text { Knowledge of discharge } \\
\text { instructions }\end{array}$ & $\begin{array}{l}\text { Correlation between literacy and } \\
\text { knowledge, } r=.67\end{array}$ & $\mathrm{P}$ \\
\hline TenHave et al. ${ }^{20}$ & CARDES/3 categories & Knowledge about heart health & LL less knowledge & $\mathrm{P}$ \\
\hline \multicolumn{5}{|l|}{ Hospitalization } \\
\hline Baker et al. ${ }^{36}$ & TOFHLA/IMA & Hospitalization & LL RR 1.69 [1.13 to 2.53$]$ & G \\
\hline Baker et al. $^{35}$ & S-TOFHLA/IMA & Hospitalization & LL RR 1.29 [1.07 to 1.55$]$ & G \\
\hline \multicolumn{5}{|l|}{ Physician Visits } \\
\hline Baker et al. $^{31}$ & TOFHLA/IMA & $\begin{array}{l}\text { Self-reported access to physician } \\
\text { visits }\end{array}$ & No relationship & $\mathrm{G}$ \\
\hline Gordon et al. ${ }^{32}$ & REALM/9th grade & Outpatient visits & $\begin{array}{l}\text { LL } 6 \text { visits/year, HL } 2 \text { visits/year, } \\
\text { statistics not reported }\end{array}$ & $\mathrm{F}$ \\
\hline \multicolumn{5}{|l|}{ Screening and Prevention } \\
\hline Scott et al. ${ }^{33}$ & S-TOFHLA/IMA & Never had influenza vaccine & LL OR 1.4 [1.1 to 1.9$]$ & $\mathrm{G}$ \\
\hline & & Never had pneumococcal vaccine & LL OR 1.2 [1.1 to 1.7$]$ & \\
\hline & & No mammogram in past 2 years & LL OR 1.5 [1.0 to 2.2$]$ & \\
\hline & & Never had a Pap smear & LL OR 1.7 [1.0 to 3.1$]$ & \\
\hline Fortenberry et al. ${ }^{34}$ & REALM/9th grade & $\begin{array}{l}\text { Appropriate screening for } \\
\text { gonorrhea }\end{array}$ & HL OR 1.36 [1.02 to 1.93 ] & $\mathrm{F}$ \\
\hline \multicolumn{5}{|l|}{ Adherence } \\
\hline Golin et al. ${ }^{38}$ & S-TOFHLA/continuous & $\begin{array}{l}\text { Adherence to antiretroviral } \\
\text { therapy }\end{array}$ & No relationship $(r=-.01)$ & $\mathrm{G}$ \\
\hline Kalichman et al. ${ }^{37}$ & TOFHLA RC/85\% correct & $\begin{array}{l}\text { Nonadherent to antiretroviral } \\
\text { therapy }\end{array}$ & LL OR 3.9 [1.1 to 13.4$]$ & G \\
\hline Frack et al. ${ }^{39}$ & $\begin{array}{l}\text { Cloze procedure/ } \\
\text { continuous }\end{array}$ & $\begin{array}{l}\text { Compliance with research } \\
\text { follow-up appointments }\end{array}$ & $\begin{array}{l}\text { Slightly lower literacy in the } \\
\text { noncompliers }\end{array}$ & $\mathrm{F}$ \\
\hline Li et al. ${ }^{40}$ & REALM/grade categories & $\begin{array}{l}\text { Compliance with breast } \\
\text { conserving therapy }\end{array}$ & No relationship & $\mathrm{F}$ \\
\hline \multicolumn{5}{|l|}{ Health Behaviors } \\
\hline $\begin{array}{l}\text { Asthma } \\
\text { Williams et al. }\end{array}$ & REALM/grade categories & MDI skills & LL score lower on MDI skills & $\mathrm{G}$ \\
\hline \multicolumn{5}{|l|}{ Smoking } \\
\hline Arnold et al. ${ }^{21}$ & REALM/continuous & Smoking rates & No difference in smoking rates & $\mathrm{G}$ \\
\hline Hawthorne $^{42}$ & Not specified & Preteenage tobacco use & LL more likely to use tobacco & $\mathrm{F}$ \\
\hline Fredrickson et al. ${ }^{41}$ & WRAT/continuous & $\begin{array}{l}\text { Rate of parental smoking Rate of } \\
\text { breastfeeding Lack of private } \\
\text { health insurance }\end{array}$ & $\begin{array}{l}\text { LL more likely to smoke LL } \\
\text { less likely to breastfeed LL less } \\
\text { likely to have private health } \\
\text { insurance }\end{array}$ & $\mathrm{P}$ \\
\hline
\end{tabular}


Table 4. Continued

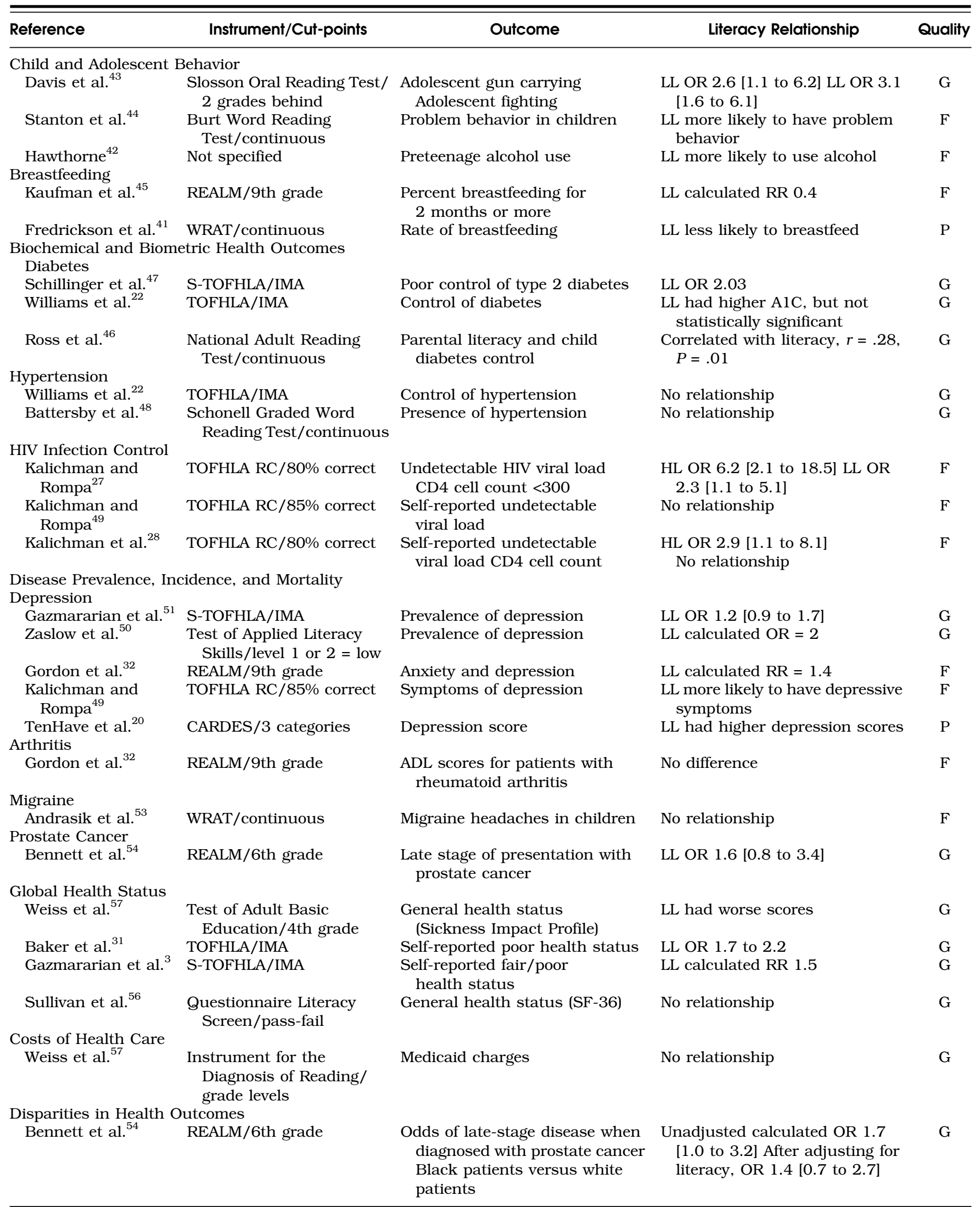

LL, lower literacy; HL, higher literacy; RR, relative risk; OR, odds ratio; G, good; F, fair; P, poor; REALM, Rapid Estimate of Adult Literacy in Medicine; TOFHLA, Test of Functional Health Literacy in Adults; S-TOFHLA, Short-TOFHLA; TOFHLA RC, TOFHLA reading comprehension only; WRAT, Wide Range Achievement Test; CARDES, Cardiovascular Dietary Education System; IMA, inadequate, marginal, adequate; MDI, metered dose inhaler; $A D L$, activities of daily living. 
One fair-quality ${ }^{45}$ and 1 poor-quality ${ }^{41}$ study found that mothers with better reading skills were more likely to breastfeed their children.

Diabetes. Three good-quality cross-sectional studies assessed the relationship between reading ability and diabetes outcomes. ${ }^{22,46,47}$ Ross et al. found no important correlation between WRAT scores for children ages 5 to 17 years with type 1 diabetes and glycemic control $(r=.1$, unadjusted). ${ }^{46}$ However, the parent's score on the National Adult Reading Test (NART) was correlated with the child's glycemic control $(r=.28 ; P=.01)$ even after adjusting for the age and gender of the child, duration of diabetes, daily insulin dose, the child's literacy score, and social class.

Williams et al. found that AlC levels were somewhat higher among those with lower literacy than those with higher literacy, but the difference was not statistically significant $(8.3 \%$ vs $7.5 \% ; P=.16)$ and they did no adjusted analyses. ${ }^{22}$ Additionally, A1C values were available for only $48 \%$ of the sample because the study was designed to assess diabetes knowledge.

Schillinger et al. measured the relationship between reading ability and glycemic control or self-reported diabetes complications among 408 patients from a public hospital internal medicine or family practice clinic and controlled for age, race/ethnicity, gender, education, language, insurance, depressive symptoms, social support, diabetes education, treatment regimen, and diabetes duration. ${ }^{47}$ Among patients with low literacy $(n=156), 20 \%$ had "tight" glycemic control (A1C < 7.2), compared with $33 \%$ of those with higher literacy $(n=198)$ (adjusted OR, 0.57; $P=.05$ ). In adjusted models, patients with lower literacy were also more likely than those with higher literacy to report retinopathy (OR, 2.33; 95\% CI, 1.2 to 4.6 ) and cerebrovascular disease (OR, 2.71; 95\% CI, 1.1 to 7.0$)$. Statistically significant relationships were not found for lower extremity amputation (OR, 2.48; 95\% CI, 0.74 to 8.3), nephropathy (OR, 1.71; 95\% CI, 0.75 to 3.9), or ischemic heart disease (OR, 1.73; $95 \%$ CI, 0.83 to 3.6), although the lack of statistical significance may be attributable to the rarity of these events, because the magnitude of association was similar.

Hypertension. Two good-quality studies evaluated the relationship between reading ability and hypertension. ${ }^{22,48}$ One used a cross-sectional design; the other, a case-control design. Neither identified an independent relationship between reading ability and presence or control of hypertension. In a bivariate comparison, Williams et al. found that patients with low literacy had higher systolic blood pressures than those with higher literacy $(155 \mathrm{~mm} \mathrm{Hg}$ vs $147 \mathrm{~mm} \mathrm{Hg} ; P=.04 ; n=408) .{ }^{22}$ However, after adjusting for age they found no relationship.

In a study by Battersby et al., patients with hypertension did not have statistically significant differences in literacy scores compared with their age-, race-, and gendermatched controls without hypertension $(n=180)$ (Schonell graded word reading test: cases 78.4 , controls 81.3 ). ${ }^{48}$
HIV Infection. Three fair-quality cross-sectional studies evaluated the relationship between reading ability and control of HIV infection. ${ }^{27,28,49}$ These studies, which were all performed by the same research group, reported on different outcomes in an overlapping sample of HIV-positive patients in Atlanta, Georgia. The studies had mixed results: some results confirmed a relationship, others did not.

Depression or Other Emotional Conditions. Two good-quality cross-sectional studies, ${ }^{50,51} 2$ fair-quality cross-sectional studies, $^{32,49}$ and 1 poor-quality cross-sectional study ${ }^{20}$ evaluated the relationship between reading ability and depression and found mixed results. One additional fairquality cross-sectional study evaluated reading ability and "emotional balance." ${ }^{52}$ All these studies used self-report questionnaires to measure depression; 2 evaluated depression in the context of specific chronic diseases (rheumatoid arthritis $^{32}$ and HIV infection ${ }^{49}$ ).

The largest good-quality study assessed depression among Medicare managed care patients using the Geriatric Depression Scale. ${ }^{51}$ This study found an unadjusted OR of being depressed of 2.7 (95\% CI, 2.2 to 3.4) for those people with lower literacy compared to those with higher literacy as assessed by the S-TOFHLA. However, after adjusting for demographic, social support, health behavior, and health status factors, the adjusted OR of 1.2 (95\% CI, 0.9 to 1.7) was much smaller and no longer statistically significant. In this case, adjustment for health status may have effaced a true relationship (overadjustment) because depression is known to affect health status directly.

Another good-quality study found in unadjusted analysis that women who had lower literacy skills were more likely to be depressed than women with higher literacy skills (estimated relative risk $=1.60 ; 95 \% \mathrm{CI}, 1.21$ to 2.12). ${ }^{50}$ No relationship was detected between women's literacy and depression or antisocial behavior among their children $(P>.10)$.

The three lower-quality studies support a modest relationship between reading ability and depression. ${ }^{20,32,49}$

Arthritis and Functional Status. One fair-quality crosssectional study of 123 consecutive patients with rheumatoid arthritis found no relationship between functional status and reading ability. ${ }^{32}$

Migraine. One fair-quality case-control study evaluated the relationship between reading ability (WRAT) and migraine headaches. There was no difference in the reading levels of the 32 children with migraine headaches and the 32 control children without migraine headaches. ${ }^{53}$

Prostate Cancer Stage. One good-quality cross-sectional study evaluated the relationship between reading ability and stage of presentation of prostate cancer. ${ }^{54}$ Men with poorer reading ability $(n=66)$ were more likely to present with late-stage prostate cancer than those with better reading ability $(n=146)(55 \%$ vs $38 \% ; P=0.022$; calculated 
OR, 2.0; 95\% CI, 1.1 to 3.7). After adjusting for race, age, and location of care, the investigators found that the relationship between literacy and stage of presentation was smaller and no longer statistically significant (OR, 1.6; 95\% CI, 0.8 to 3.4 ), suggesting important confounding between race and literacy in this population.

Global Health Status Measures. Four good-quality crosssectional studies evaluated the relationship between reading ability and a global health status measure (Table 4). ${ }^{3,31,55,56}$ Three studies found an association between poorer reading ability and poorer health status ${ }^{3,31,55}$; the fourth found no relationship. ${ }^{56}$

Weiss et al. assessed global health status using the Sickness Impact Profile (SIP) in a group of relatively young participants (mean age 29 years). ${ }^{55}$ After adjusting for age, gender, ethnicity, marital status, insurance status, occupation, and income, people who scored below the fourth grade level on the Test of Adult Basic Education and Mott Basic Language Skills Program scored worse on the SIP (10.4 vs $6.0 ; P=.02$ ).

Baker et al. examined self-reported health status among 2,659 patients at 2 public hospitals by asking whether their health was excellent, good, fair, or poor. ${ }^{31}$ After controlling for age, gender, race, and socioeconomic indicators, they found that patients with lower literacy had about 2 times the odds of reporting poor health compared to patients with higher literacy. Gazmararian et al. also examined the relationship between literacy and self-reported health status. They queried 3,260 patients enrolled in a Medicare managed care health plan about their health status using the same question. In their bivariate comparison, patients with lower literacy were more likely to self-report fair or poor health than patients with higher literacy $(43 \%$ vs $20 \% ; P<.001) .^{3}$

In contrast, Sullivan et al. measured general health status among patients with type 2 diabetes using the Medical Outcomes Study Short Form-36 (SF-36) ${ }^{56}$; they assessed literacy using the Questionnaire Literacy Screen (QLS), which was being developed at the time of the study. In an unadjusted analysis, they found no difference in scores on the SF-36 according to whether the subject "passed" or "failed" the QLS.

\section{Relationship Between Reading Ability and Costs of Health Care}

One study of good quality examined the relationship between reading ability and cost of health care ${ }^{57}$ It found no relationship between literacy and Medicaid charges gathered from Medicaid records $\left(r^{2}=.0016 ; P=.43\right)$. In subgroup analyses examining inpatient care, outpatient care, and emergency care, the investigators did not identify any relationship between literacy and charges. Most patients in this study enrolled in Medicaid because of pregnancy rather than medical need or medical indigence. A subsequent statistical analysis of nonpregnant patients $(n=74)$ found that the 18 patients with a reading level at or below third grade had higher mean Medicaid charges than the 56 who read above the third grade level $(\$ 10,688$ vs $\$ 2,891$; $P=.025) .^{58}$

\section{Disparities in Health Outcomes or Health Care Service Use}

Only one good-quality cross-sectional study directly examined the role of reading ability as a mediator of disparities in health outcomes or health care service use. In this study, black patients were significantly more likely than white patients to present with late-stage prostate cancer (unadjusted $49.5 \%$ vs $35.9 \% ; P=.045$; calculated OR, 1.7; 95\% CI, 1.0 to 3.2). ${ }^{54}$ After adjustments for literacy, age, and location of care, the odds ratio was smaller and no longer statistically significant (OR, 1.4; 95\% CI, 0.7 to 2.7). The authors suggest that literacy may be mediating some of the racial difference in stage of presentation for prostate cancer. As noted earlier in the results, literacy was also not statistically significant after adjustment for covariates.

\section{DISCUSSION}

Based on the published data identified by our systematic review, reading ability is related to knowledge about health and health care, hospitalization, global measures of health, and some chronic diseases. People who read at lower levels are generally 1.5 to 3 times more likely to have an adverse outcome as people who read at higher levels. We found less information on the relationship between literacy and health care costs and the role of literacy in mediating disparities in health outcomes according to race, ethnicity, culture, or age.

Although our review examines the same topic as previous reviews, ${ }^{4,59}$ our approach has several advantages. We have applied a more rigorous approach to identifying relevant studies using inclusive search terms but also applying stricter inclusion criteria. We also assessed the quality of available research. We carefully examined strategies for controlling for confounding to determine where bias might be responsible for conflicting evidence. Given our systematic approach, we could better examine the effects of potential confounders on the relationship between literacy and health outcomes and generate hypotheses about how literacy exerts its effects.

\section{Analyzing the Relationship Between Literacy and Health Outcomes}

Studying the relationship between reading ability and health is important for three reasons: to understand better the true etiology of poor health outcomes; to identify a potential clinical marker of patients at risk for poor outcomes; and to inform the development of interventions. In this review, we have focused on understanding etiology. 
A key aspect of understanding the true etiologic relationship between reading ability and health is the analysis of confounding factors. If researchers do not appropriately address confounders, they risk misestimating the independent relationship between reading ability and poor health, leading to faulty conclusions and policy decisions, including ineffective interventions. For example, reading ability may be associated with a lack of health insurance or poverty, both of which affect health outcomes. If investigators do not address those variables in their analysis, the reported independent relationship between literacy and outcomes may be inaccurate. However, overadjustment (adjusting for variables that are actually in the pathway from low reading ability to adverse health) can also cause misestimation.

Two studies in our review exemplify the complexity of evaluating confounding in this body of literature. ${ }^{51,54}$ In their study evaluating the relationship between reading ability and depression, Gazmararian et al. found an important bivariate relationship before adjusting for confounders; after adjusting for health status, the relationship became weaker and was not statistically significant. ${ }^{51}$ However, because depression itself is related to worse health status, adjusting for health status in analysis may not lead to a better (unbiased) estimate of the relationship between reading ability and depression.

Bennett et al. found that stage of presentation of prostate cancer was related to both reading ability and race in 2 different bivariate analyses. ${ }^{54}$ When both variables were put into a single model, the magnitude of the relationship to stage of presentation became smaller for both variables. One might interpret this finding as showing that literacy mediates part of the relationship between race and stage of presentation, but an effect of race mediating part of the relationship between literacy and health outcomes is an equally plausible explanation.

\section{Measurement of Literacy}

From the available evidence in our review, we cannot say that one instrument measures the skills necessary for functioning in a health care environment better than another, or that one instrument predicts health outcomes better than another. In fact, the high correlation $(r=.74$ to .88 ) between the various instruments suggests that they measure essentially the same underlying construct. ${ }^{11,12}$ Although most studies used well-validated instruments, we did not systematically evaluate the evidence of literacy instrument validation other than for the WRAT, REALM, and TOFHLA. We also included 2 studies ${ }^{20,56}$ that used new or incompletely validated instruments and 1 study that did not identify the instrument used. ${ }^{42}$ Including these studies allows the reader to see how researchers are taking novel approaches toward understanding the connection between literacy and health without compromising our overall conclusions.

Analysts can study each of these instruments as a continuous measure or categorized into literacy levels.
Cut-points for categories varied across the studies, but the relationship between literacy and health outcomes remained stable. For many outcomes, literacy probably acts like a continuous variable, with better outcomes for higher literacy regardless of the cut-point. For some outcomes, however, literacy may have a threshold effect, meaning that a certain level of literacy is needed for a good outcome and higher literacy beyond the threshold has no added benefit. Future research should investigate such thresholds further.

\section{Limitations of This Systematic Review}

Our systematic review should be interpreted in the context of several limitations. As with all systematic reviews, its findings reflect the quality of the published literature. The limitations in the available studies include use of a wide variety of reading measures and cut-points for analysis, making comparisons between studies difficult; predominance of cross-sectional study designs, which leads to inability to measure incident outcomes or assign cause and effect; inconsistent and potentially inappropriate control for covariates; lack of reporting of appropriate statistical measures (i.e., use of $P$ values without measures of magnitude or confidence intervals), making it difficult to determine whether null findings represent true lack of effect or limitations in power; lack of adjustment for multiple comparisons; lack of reporting how health outcomes were assessed, particularly whether the questionnaires were presented in ways that would allow accurate responses by participants with limited literacy; focus on knowledge rather than more meaningful health outcomes; and the wide range of outcomes assessed, making it difficult to compare studies.

\section{Future Research}

Future research can build on previous work to elucidate better the relationship between literacy and health. Future studies should examine more closely and rigorously the factors that mediate the relationship between literacy and important health outcomes.

For example, investigators should examine the question of whether poor reading ability is really the cause of adverse health outcomes or whether it serves as a marker for other problems, such as low socioeconomic status, poor self-efficacy, low trust in medical providers, or impaired access to care, that are the actual sources of poor health. Such information is also crucial to designing and testing future intervention studies.

More prospective cohort studies that measure outcomes and literacy over time will provide a better understanding of the relationships among literacy, age, and health outcomes and the extent to which health status actually affects literacy.

We also need further development of measurement techniques for low-literacy populations. Literacy may systematically affect the quality of data gathered by self-report 
questionnaires, ${ }^{60}$ perhaps even if they are administered orally. This may be particularly important when using Likert-type scales. ${ }^{61}$ Evaluation of questionnaire responses in light of other objective measures may help to clarify whether literacy affects self-report and how to design questionnaires that are valid and consistent across literacy levels.

In addition to these research implications, our findings have implications for clinicians and medical educators. Foremost, providers should recognize that low literacy is associated with a variety of adverse health conditions. Although we did not explore this issue directly, they should also know that low literacy is common and, when unrecognized, presents a barrier to effective care. They should check for understanding, use literacy-independent teaching methods, and reinforce education over time. The question of whether specific interventions can mitigate the effects of low literacy is examined in the full report. ${ }^{7}$ Our data do not inform the question of whether providers should routinely assess literacy, but doing so may help to target effective interventions.

\section{Conclusion and Implications}

Despite the important work ahead of us, the research on literacy and health has come a long way in the last two decades. Our systematic review confirms that low literacy is associated with a range of adverse health outcomes. Future studies that explore the nature of the literacy-health relationship are needed; particularly ones that can identify factors that mediate the relationship and can serve as targets for future intervention research.

This study was developed by the RTI International-University of North Carolina Evidence-based Practice Center under contract to the Agency for Healthcare Research and Quality (29002-0016), Rockville, Md. The Robert Wood Johnson Foundation through its Clinical Scholars Program at UNC-Chapel Hill provided support to enable Dr. DeWalt to participate in this work. The authors thank Loraine Monroe and Tammeka Swinson of RTI International for dedicated efforts in producing this manuscript.

\section{REFERENCES}

1. Kirsch I, Jungeblut A, Jenkins L, Kolstat A. Adult Literacy in America: A First Look at the Findings of the National Adult Literacy Survey, 3rd ed. Washington, DC: National Center for Education, U.S. Department of Education; April 2002.

2. Williams MV, Parker RM, Baker DW, et al. Inadequate functional health literacy among patients at two public hospitals. JAMA. 1995;274:1677-82.

3. Gazmararian JA, Baker DW, Williams MV, et al. Health literacy among Medicare enrollees in a managed care organization. JAMA. 1999;281:545-51.

4. Health literacy: report of the Council on Scientific Affairs. Ad Hoc Committee on Health Literacy for the Council on Scientific Affairs, American Medical Association. JAMA. 1999;281:552-7.

5. Nutbeam D. Health literacy as a public health goal: a challenge for contemporary health education and communication strategies into the 21st century. Health Promot Int. 2000;15:259-67.
6. Berkman ND, DeWalt DA, Pignone MP, et al. Literacy and Health Outcomes. Research Triangle Park, NC: RTI International-University of North Carolina Evidence-based Practice Center; October 24, 2003.

7. Berkman ND, DeWalt DA, Pignone MP, et al. Literacy and Health Outcomes. Research Triangle Park, NC: RTI InternationalUniversity of North Carolina Evidence-based Practice Center; January 2004.

8. Selden CR, Zorn M, Ratzan S, Parker RM. Health Literacy. Current Bibliographies in Medicine, no. 2000-1, vol. 2003. Bethesda, Md: National Library of Medicine; 2000.

9. Rudd RE, Colton T, Schacht R. An Overview of the Medical and Public Health Literature Addressing Literacy Issues: An Annotated Bibliography. National Center for the Study of Adult Learning and Literacy; January 2000. Available at: http:// www.hsph.harvard.edu/health/literacy/literature.html.

10. West SL, King V, Carey TS, et al. Systems to Rate the Strength of Scientific Evidence. AHRQ Publication no. 02-E016. Agency for Healthcare Research and Quality; 2002.

11. Davis TC, Long SW, Jackson RH, et al. Rapid estimate of adult literacy in medicine: a shortened screening instrument. Fam Med. 1993;25:391-5.

12. Parker RM, Baker DW, Williams MV, Nurss JR. The test of functional health literacy in adults: a new instrument for measuring patients' literacy skills. J Gen Intern Med. 1995;10:537-41.

13. Baker DW, Williams MV, Parker RM, Gazmararian JA, Nurss J. Development of a brief test to measure functional health literacy. Patient Educ Couns. 1999;38:33-42.

14. Wilkinson GS. Wide Range Achievement Test: Administration Manual. Wilmington, Del: Wide Range, Inc.; 1993.

15. Davis TC, Arnold C, Berkel HJ, Nandy I, Jackson RH, Glass J. Knowledge and attitude on screening mammography among low-literate, low-income women. Cancer. 1996;78:1912-20.

16. Lindau ST, Tomori C, Lyons T, Langseth L, Bennett CL, Garcia P. The association of health literacy with cervical cancer prevention knowledge and health behaviors in a multiethnic cohort of women. Am J Obstet Gynecol. 2002;186:938-43.

17. Miller LG, Liu H, Hays RD, et al. Knowledge of antiretroviral regimen dosing and adherence: a longitudinal study. Clin Infect Dis. 2003;36:514-8.

18. Moon RY, Cheng TL, Patel KM, Baumhaft K, Scheidt PC. Parental literacy level and understanding of medical information. Pediatrics. 1998; 102:e25.

19. Spandorfer JM, Karras DJ, Hughes LA, Caputo C. Comprehension of discharge instructions by patients in an urban emergency department. Ann Emerg Med. 1995;25:71-4.

20. TenHave TR, Van Horn B, Kumanyika S, Askov E, Matthews Y, Adams-Campbell LL. Literacy assessment in a cardiovascular nutrition education setting. Patient Educ Couns. 1997;31:139-50.

21. Arnold CL, Davis TC, Berkel HJ, Jackson RH, Nandy I, London S. Smoking status, reading level, and knowledge of tobacco effects among low-income pregnant women. Prev Med. 2001;32:313-20.

22. Williams MV, Baker DW, Parker RM, Nurss JR. Relationship of functional health literacy to patients' knowledge of their chronic disease. A study of patients with hypertension and diabetes. Arch Intern Med. 1998;158:166-72.

23. Williams MV, Baker DW, Honig EG, Lee TM, Nowlan A. Inadequate literacy is a barrier to asthma knowledge and self-care. Chest. 1998; 114:1008-15.

24. Conlin KK, Schumann L. Literacy in the health care system: a study on open heart surgery patients. J Am Acad Nurse Pract. 2002; 14:38-42.

25. Wilson FL, McLemore R. Patient literacy levels: a consideration when designing patient education programs. Rehabil Nurs. 1997;22:311-7.

26. Gazmararian JA, Parker RM, Baker DW. Reading skills and family planning knowledge and practices in a low-income managed-care population. Obstet Gynecol. 1999;93:239-44.

27. Kalichman SC, Rompa D. Functional health literacy is associated with health status and health-related knowledge in people living 
with HIV-AIDS. J Acquir Immune Defic Syndr Hum Retrovirol 2000;25:337-44.

28. Kalichman SC, Benotsch E, Suarez T, Catz S, Miller J, Rompa D. Health literacy and health-related knowledge among persons living with HIV/AIDS. Am J Prev Med. 2000;18:325-31.

29. Kalichman SC, Rompa D, Cage M. Reliability and validity of selfreported CD4 lymphocyte count and viral load test results in people living with HIV/AIDS. Int J STD AIDS. 2000;11:579-85.

30. Miller CK, O'Donnell DC, Searight HR, Barbarash RA. The Deaconess Informed Consent Comprehension Test: an assessment tool for clinical research subjects. Pharmacotherapy. 1996;16:872-8.

31. Baker DW, Parker RM, Williams MV, Clark WS, Nurss J. The relationship of patient reading ability to self-reported health and use of health services. Am J Public Health. 1997;87:1027-30.

32. Gordon MM, Hampson R, Capell HA, Madhok R. Illiteracy in rheumatoid arthritis patients as determined by the Rapid Estimate of Adult Literacy in Medicine (REALM) score. Rheumatology. 2002;41:750-4

33. Scott TL, Gazmararian JA, Williams MV, Baker DW. Health literacy and preventive health care use among Medicare enrollees in a managed care organization. Med Care. 2002;40:395-404.

34. Fortenberry JD, McFarlane MM, Hennessy M, et al. Relation of health literacy to gonorrhoea related care. Sex Transm Infect. 2001;77:206-11.

35. Baker DW, Gazmararian JA, Williams MV, et al. Functional health literacy and the risk of hospital admission among Medicare managed care enrollees. Am J Public Health. 2002;92:1278-83.

36. Baker DW, Parker RM, Williams MV, Clark WS. Health literacy and the risk of hospital admission. J Gen Intern Med. 1998;13:791-8.

37. Kalichman SC, Ramachandran B, Catz S. Adherence to combination antiretroviral therapies in HIV patients of low health literacy. J Gen Intern Med. 1999;14:267-73.

38. Golin CE, Liu H, Hays RD, et al. A prospective study of predictors of adherence to combination antiretroviral medication. $J$ Gen Intern Med. 2002;17:756-65.

39. Frack SA, Woodruff SI, Candelaria J, Elder JP. Correlates of compliance with measurement protocols in a Latino nutritionintervention study. Am J Prev Med. 1997;13:131-6.

40. Li BD, Brown WA, Ampil FL, Burton GV, Yu H, McDonald JC. Patient compliance is critical for equivalent clinical outcomes for breast cancer treated by breast-conservation therapy. Ann Surg. 2000;231:883-9.

41. Fredrickson DD, Washington RL, Pham N, Jackson T, Wiltshire J, Jecha LD. Reading grade levels and health behaviors of parents at child clinics. Kans Med. 1995;96:127-9.

42. Hawthorne G. Preteenage drug use in Australia: the key predictors and school-based drug education. J Adolesc Health. 1997;20:38495

43. Davis TC, Byrd RS, Arnold CL, Auinger P, Bocchini JAJ. Low literacy and violence among adolescents in a summer sports program. J Adolesc Health. 1999;24:403-11.

44. Stanton WR, Feehan M, McGee R, Silva PA. The relative value of reading ability and IQ as predictors of teacher-reported behavior problems. J Learn Disabil. 1990;23:514-7.

45. Kaufman H, Skipper B, Small L, Terry T, McGrew M. Effect of literacy on breast-feeding outcomes. South Med J. 2001;94:293-6.

46. Ross LA, Frier BM, Kelnar CJ, Deary IJ. Child and parental mental ability and glycaemic control in children with type 1 diabetes. Diabet Med. 2001;18:364-9.

47. Schillinger D, Grumbach K, Piette J, et al. Association of health literacy with diabetes outcomes. JAMA. 2002;288:475-82.

48. Battersby C, Hartley K, Fletcher AE, et al. Cognitive function in hypertension: a community based study. J Hum Hypertens. 1993; 7:117-23.

49. Kalichman SC, Rompa D. Emotional reactions to health status changes and emotional well-being among HIV-positive persons with limited reading literacy. J Clin Psychol Med Settings. 2000;7:203-11.

50. Zaslow MJ, Hair EC, Dion MR, Ahluwalia SK, Sargent J. Maternal depressive symptoms and low literacy as potential barriers to employment in a sample of families receiving welfare: are there twogenerational implications? Women Health. 2001;32:211-51.

51. Gazmararian J, Baker D, Parker R, Blazer DG. A multivariate analysis of factors associated with depression: evaluating the role of health literacy as a potential contributor. Arch Intern Med. 2000;160:3307-14.

52. Fisch M, Unverzagt F, Hanna M, Bledsoe P, Menke C, Cornetta K. Information preferences, reading ability, and emotional changes in outpatients during the process of obtaining informed consent for autologous bone-marrow transplantation. J Cancer Educ. 1998;13:71-5

53. Andrasik F, Kabela E, Quinn S, Attanasio V, Blanchard EB, Rosenblum EL. Psychological functioning of children who have recurrent migraine. Pain. 1988;34:43-52.

54. Bennett CL, Ferreira MR, Davis TC, et al. Relation between literacy, race, and stage of presentation among low-income patients with prostate cancer. J Clin Oncol. 1998;16:3101-4.

55. Weiss BD, Hart G, McGee DL, D'Estelle S. Health status of illiterate adults: relation between literacy and health status among persons with low literacy skills. J Am Board Fam Pract. 1992;5:257-64.

56. Sullivan LM, Dukes KA, Harris L, Dittus RS, Greenfield S, Kaplan $\mathrm{SH}$. A comparison of various methods of collecting self-reported health outcomes data among low-income and minority patients. Med Care. 1995;33:AS183-AS194.

57. Weiss BD, Blanchard JS, McGee DL, et al. Illiteracy among Medicaid recipients and its relationship to health care costs. J Health Care Poor Underserved. 1994;5:99-111.

58. Weiss BD, Palmer R. Relationship between health care costs and very low literacy skills in a medically needy and indigent Medicaid population. J Am Board Fam Pract. 2004;17:44-7.

59. Rudd RE, Moeykens BA, Colton TC. Health and literacy: a review of medical and public health literature. In: Comings J, Garners B, Smith C, eds. Annual Review of Adult Learning and Literacy. New York, NY: Jossey-Bass; 1999:1-28.

60. Sentell TL, Ratcliff-Baird B. Literacy and comprehension of Beck Depression Inventory response alternatives. Community Ment Health J. 2003;39:323-31.

61. Williams SA, Swanson MS. The effect of reading ability and response formats on patients' abilities to respond to a patient satisfaction scale. J Contin Educ Nurs. 2001;32:60-7.

62. Davis TC, Crouch MA, Long SW, et al. Rapid assessment of literacy levels of adult primary care patients. Fam Med. 1991; 23:433-5.

63. Nurss JR, Parker RM, Williams MV, Baker DW. Test of Functional Health Literacy in Adults Technical Report. Georgia State University; May 1998. 